\section{Pharmacovigilance on drugs for headache and pain}

Individuals suffering from chronic headache or pain are, among chronic sufferers, the most sensitive to develop health damage due to overuse or abuse of analgesics or other pain-controlling drugs. Pharmacovigilance is a term that describes the activities of control and surveillance on adverse events to drugs. Three different branches are devoted to that activity: post-market surveillance, investigation of product complaints, and monitoring of adverse reactions. Any product registered in each country is continously under control of the local authority to comply with the pre-registration standards of quality, efficacy and safety. Patients suffering from headache disorders or other pain syndromes are subject to long-term treatment with various substances for the control of pain or of headache or for the prophylaxis of that disabling clinical conditions. Thus, this category of patients is highly exposed to drug-related side effects. Various organizations run Web sites to control over time the safety of drugs, with the purpose to monitor trends in reported suspected adverse reactions. Reports received by each organization are prioritized in terms of severity or likely casuality, and are analyzed with any previous similar reports on the same product. The management of the information on critical safety issue risk implements then additional safety studies to optimize the benefit-risk balance of those compounds.

Adverse drug reactions (ADR) monitoring is carried out through spontaneous reporting of adverse reactions incidentally encountered by doctors, pharmacists and dentists unfortunately still on a voluntary basis. These health professionals should be encouraged to report all suspected ADR irrespective of their seriousness, unsureness of casualty or relative rarity. On that basis, local authorities may decide for labelling changes, insertion of warnings, additions of precautionary statements, de-registration, suspension of registration, or batch recall for the suspected substances.

The Web is an important information channel for disseminating that information on ADR through scientific journals, pharmacovigilance bulletins and national or international agencies of health safety, and for stimulating the use of guidelines and procedures on reporting ADR.

Many countries present information on pharmacovigilance activities on public health ministry, agency or inspectorate Web sites, several of them still in national language only.

The following Web sites dedicated to pharmacovigilance have been selected for the feasibility to obtain information on pharmacovigilance or to submit reports on that argument.

\section{Non-governmental Web sites}

World Health Organization (WHO). The Essential Drugs and Medicine Policy (EDM) section provides recommendations about medicinal products, including safety use. http://www.who.int/

The European Agency for the Evaluation of Medicinal Products (EMEA). The EU Agency site contains many reports on drug safety. http://www.emea.eu.int/
Heads of Agencies (HeA). The common website for the medicine authorities in the European Union. A connection point to reach Websites of the health authorities of all EU countries. http://heads.medagencies.org/

\section{Governmental Web sites}

Food and Drug Administration (FDA). The USA governmental Website contains the most complete database designed to support the post-marketing safety surveillance program.

Center for Drug Evaluation and Research (CDER). http://www.fda.gov/cder/aers/defaults.htm. Warning, pharmacovigilance and patient information can be obtained.

Medical Products Reporting Program (MedWatch). http://www.fda.gov/medwatch/index.htm. Voluntary or mandatory reporting of adverse events and product problems can be submitted throughout this gate.

Medicines Control Agency (MCA). The UK Committee on Safety of Medicines (CSM) section provides information on the safety of medical products, new drugs under intensive surveillance and current problems in pharmacovigilance. http://www.mca.gov.uk/aboutagency/regframework/csm/csmhomemain.htm

French Agency for Sanitary Safety of Health Products (AFSSAPS). A very exhaustive site on drug safety information.

Regional Pharmacovigilance Centres (CRPV). The network of 31 French Pharmacovigilance Centres (CRPV) can be reached. The contact person for each CRPV is reported with full coordinates. http://agmed.sante.gouv. fr/htm/2/2200c.htm

Federal Institute for Drugs and Medical Devices (BfArM). This official German organization is devoted to collect data and disseminate information on ADR, as well as to revoke the marketing license of suspected drugs. $\underline{\text { http://www.bfarm.de.gb ver/ }}$

Italian Ministry of Health. The section dedicated to pharmacovigilance of the Italian Ministry of Health reports a bi-monthly bullettin and a databank on ADR.

Drugs Evaluation and Pharmacovigilance. The communication network is limited to official reports coming from hospitals, local health units and pharmacuetical companies. The voluntary reports from physicians or pharmacists, but not from other health professionals and patients, must be collected exclusively throughout this official gate. http://www.sanita.it/sanita/farmacovigilanzal

\section{Scientific journals}

Pharmacoepidemiology and Drug Safety. http://www3.interscience. wiley.com/cgi-bin/jtoc? ID $=5669$

European Journal of Clinical Pharmacology. http://link.springer.de/link/service/journals/00228/index.htm

The accuracy on monitoring and reporting ADR from health care professionals by using both traditional or the newest available online recording facilities will provide a substantial amelioration in the management and cure of patients with headache and chronic pain, but also an immense improvement in their holistic care. 